\title{
Intermediate-depth earthquakes beneath the Pamir- Hindu Kush Region: Evidence for collision between two opposite subduction zones *
}

\author{
Xiaoting Lou Chen Cai Chunquan Yu and Jieyuan Ning * \\ Department of Geophysics, School of Earth and Space Sciences, Peking University, Beijing 100871, China
}

\begin{abstract}
We employed a double-difference algorithm (hypoDD) to relocate earthquakes within the region bounded by $66^{\circ} \mathrm{E}-78^{\circ} \mathrm{E}$ and $32^{\circ} \mathrm{N}-42^{\circ} \mathrm{N}$ in the period of $1964-2003$ reported by the International Seismological Center (ISC). The improved hypocentral locations delineate a double-layered Wadati-Benioff zone in the eastern Hindu Kush intermediate seismic belt. Based on this feature and other evidences, we propose that the intermediate-depth earthquakes beneath the Pamir-Hindu Kush region may occur in two collided subduction zones with opposite dip directions.
\end{abstract}

Key words: continental dynamics; Pamir-Hindu Kush; intermediate seismic zone; earthquake relocation CLC number: P315.2 Document code: A

\section{Introduction}

Located at the western Himalayan syntaxis, the Pamir-Hindu Kush region is one of the most active regions of intermediate-depth earthquakes which are not obviously related to well-defined subducting slabs inspite of some geophysical evidences (e.g., Vinnik et al, 1977; Roecker, 1982; Mellors et al, 1995; Van der Voo et al, 1999; Lei and Zhao, 2002; Huang and Zhao, 2006; Negredo et al, 2007). The accurate spatial distribution of those earthquakes and their focal mechanism solutions are helpful to understanding the actual geometry as well as the stress state of possibly existing subduction zones in this region, and can provide constraints on plate interaction and tectonic evolution in the Pamir-Hindu Kush region.

As early as 1950s, Gutenberg and Richter (1954) and Richter (1958) located several mantle earthquakes with depth greater than $200 \mathrm{~km}$ beneath the Pamir-Hindu Kush region. Since then, a number of seismological studies for this region have been carried out (e.g. Nowroozi, 1971; Billington et al, 1977; Vinnik et al, 1977; Chatelain et al, 1980; Roecker et al, 1980; Roecker, 1982; Fan et al, 1994; Ning and Zang, 1990; Mellors et al, 1995; Zhu et al, 1997; Pegler and Das, 1998; Liu,

\footnotetext{
* Received 31 August 2009; accepted in revised form 12 November 2009; published 10 December 2009.

- Corresponding author. e-mail: njy@pku.edu.cn
}

1999; Pavlis and Das, 2000; Lou et al, 2007). An S-shaped intermediate-depth seismic zone in this region was identified, including two segments with obviously different strikes and dip directions. However, its formation is still under debate. There are two major geodynamic models: one is two-slab model and the other is one-slab with overturning model. The two-slab model suggests that there are originally two subducting slabs with opposing polarities (Roecker et al, 1980; Chatelain et al, 1980; Ning and Zang, 1990; Fan et al, 1994; Lou et al, 2007). The two main arguments for this model are seismic gap of about $100 \mathrm{~km}$ wide between the Pamir and the Hindu Kush seismic zones, as well as the geometrical relationship between the intermediate-depth earthquakes beneath Pamir and the intense shallow earthquakes along the northern boundary of Pamir. However, this model cannot clearly explain the geometrical consistency between the two seismic zones. On the other hand, the one-slab model favors a single subducting slab dipping northward, of which the Pamir part overturned at some point and formed the current two adjacent Wadati-Benioff (W-B) zones with opposite dip directions (Vinnik et al, 1977; Billington et al, 1977; Pegler and Das, 1998; Pavlis and Das, 2000). A remarkable alignment of the Pamir and the Hindu Kush seismic zones around the boundary region is the main argument for this model. However, it is unable to satisfactorily explain the geometrical relationship between 
the intermediate-depth earthquakes and the intense shallow earthquakes in the Pamir region. Secondly, it contradicts the geological implication of the ophiolite belt in the northern Pamir zone (Verma and Sekhar, 1985). There should be a south-dipping subduction zone to the south of this suit of rocks. The third difficulty of the one-slab model faces is that the Punjab Wedge cannot supply enough material diversely subducting into the mantle in the Pamir region although it can exert strong extrusion to Pamir.

With the help of forty years high quality data from the International Seismological Center (ISC) and a robust earthquake relocation technique (HypoDD, Waldhauser and Ellsworth, 2000), we reexamine the distribution of the earthquakes beneath the Pamir-Hindu Kush region. Then we discuss the possible geodynamic processes occurred in this region based on the relocation results and corresponding analyses. Finally, we propose that the intermediate-depth earthquakes beneath the Pamir-Hindu Kush region are caused by two collided subduction zones with opposite dip directions.

\section{Data processing and the applicability of the HypoDD program}

The ISC lists 10224 earthquakes in the region bounded by $66^{\circ} \mathrm{E}-78^{\circ} \mathrm{E}$ and $32^{\circ} \mathrm{N}-42^{\circ} \mathrm{N}$ in $1964-2003$. In order to improve the earthquake location accuracy, we use the double-difference program HypoDD developed by Waldhauser et al (Waldhauser and Ellsworth, 2000; Waldhauser, 2001) to relocate the earthquakes. Of the 10224 events listed in the catalog, 7655 have at least six $\mathrm{P}$ wave arrival times recorded by 279 stations in the region within $60^{\circ} \mathrm{E}-90^{\circ} \mathrm{E}$ and $20^{\circ} \mathrm{N}-50^{\circ} \mathrm{N}$. In total, there are about $135000 \mathrm{P}$ and $42000 \mathrm{~S}$ wave arrival picks available. The catalog phase arrival times were assigned relative a priori weights of $1,0.75,0.5,0.25$, and 0 for five kinds of pick quality: impulsive, emergent, less emergent, questionable, and null. About 269365 P-phase pairs and 212354 S-phase pairs were selected. The average offset between linked events is $10.74 \mathrm{~km}$. The double-difference travel time match in the hypoDD program preserved 6018 out of the 7655 events. Then 4 751 events were grouped into 182 clusters recorded by 80 stations. The other 1267 events were outliers. Finally 2134 events were successfully relocated and 1479 of them have depth greater than $70 \mathrm{~km}$. The Engdahl et al (1998) algorithm has been used to significantly improve routine hypocenter determinations by the ISC and the
EHB Bulletin published at http://www.isc.ac.uk/EHB/ index.html. However, to utilize as many events as possible in our computations and avoid the misuse of the depth phases when there is complicated topographical relief, we only use the ISC catalog.

Before conducting the relocation procedure on the catalog phase data, we carried out several tests to verify the program by using theoretical phase arrival data. Just to name a few, taking the hypocenters given in the ISC catalog as inputs, we firstly calculated $\mathrm{P}$ and $\mathrm{S}$ arrival times at available stations by a ray tracing program (Tian and Chen, 2005), and then did the relocation. In this case the root-mean-square (RMS) error in hypocenter locations is less than $0.02 \mathrm{~km}$. We also tested the influences of initial earthquake locations and phase-pick quality by giving random perturbations to the initial locations and phase arrival times in the theoretical phase data. When adding random perturbations with a maximum of $20 \mathrm{~km}$ to initial locations, RMS error in hypocenter location is less than $0.5 \mathrm{~km}$. Further addition of random perturbations with a maximum of $0.2 \mathrm{~s}$ to the theoretical phase arrival times, results in a RMS error in hypocenter location of less than $0.7 \mathrm{~km}$. In our computations, we adopted a 1-D layered wave-velocity model suggested by Zhu et al (1997) after we confirmed that the relocation result is stable upon a small change in wave-velocity. We also applied the bootstrap resampling approach (Efron, 1982) to the events by adding random perturbations with a maximum of $1.0 \mathrm{~s}$, an overrated value, to the phase arrival times reported by the ISC, relocated all events with these bootstrap-sample data, and calculated the shifts in relocated hypocentral locations. The same process was repeated 50 times, and the cumulative results are presented in Figures 1a-1c. The results show that the relocation precision in north-south direction is the best because most seismic stations are located to the north and south of the study area. The variation range of the $95 \%$ confidence region in this direction is about $\pm 8 \mathrm{~km}$. The ones in the east-west and vertical directions within 95\% confidence levels are $\pm 12 \mathrm{~km}$ and $\pm 20 \mathrm{~km}$, respectively. Variations in station distribution for each event pair can introduce errors in relative event locations. We applied the Jackknife method (e.g., Efron, 1982) to estimate the variance of errors in each coordinate direction. The procedure involves repeated relocation, each time subsampling the data by deleting one station. Resulting errors in the three directions are all less than $5 \mathrm{~km}$. 

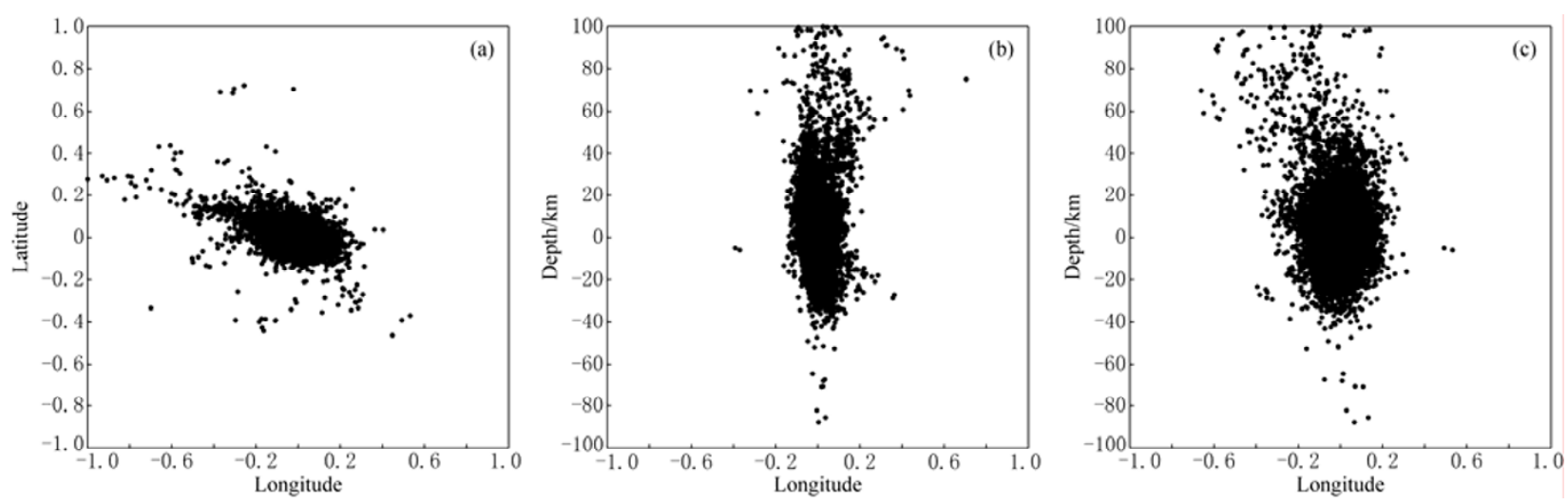

Figure 1 Cumulative relocation shifts with bootstrap-resample data by adding random perturbations with a maximum of $1.0 \mathrm{~s}$ to the phase arrival times reported by the ISC. (a) Horizontal profile; (b) east-west profile; (c) north-south profile.

To sum up, all these tests proved that the double-difference algorithm developed by Waldhauser and Ellsworth (2000) is appropriate to refine the spatial distribution of the earthquakes beneath the Pamir-Hindu Kush region.

\section{Results and discussion}

Figure 2 shows the epicenters of the relocated earthquakes in the Pamir-Hindu Kush region color-coded by focal depth. A well-known feature pointed out by previous authors (e.g., Roecker et al, 1980; Chatelain et al, 1980; Ning and Zang, 1990; Lou et al, 2007), the S-shaped, $700 \mathrm{~km}$ long intermediate-depth seismic zone with few shallow events occurred above them, is further exhibited. The seismic zone has an obvious overturning change of dip direction near $36.8^{\circ} \mathrm{N}$. Separated by the profile GG' shown in Figure 2, the Hindu Kush seismic zone dips northward and the Pamir seismic zone dips southeast although the limited number of high-precision events after relocation prevents us from providing clearer image. It should be mentioned that the dip direction of the Wadati-Benioff zone in Hindu Kush is varying: the dip direction of the shallower part (green dots) is different from the one of the deeper part (blue dots). If these two parts of the W-B zone had located in a northward subducting slab which might be broken later, the shallower part would have rotated at least $20^{\circ}$ anti-clockwise relative to the deeper part. This image is important because it at least means that in the shallower part the eastern segment of the slab moves faster than the western segment in Hindu Kush region. This is in accordance with the tectonic feature at the Earth's surface in this region. However, in the deeper part the slab seems not having this kind of difference, at least not significant. Therefore, it is more likely that the shallower and the deeper parts of the W-B zone locate in decoupled continental and the oceanic plates respectively, which was revealed earlier by geophysical inversion (Roecker, 1982; Mellors et al, 1995).

Most shallow-depth earthquakes in this region are distributed to the north of $36^{\circ} \mathrm{N}$ along the Main Pamir Thrust (MPT) and the Darvaz Fault, which is similar to the results of Ning and Zang (1990) and Fan et al (1994). In particular, the seismic belt along the MPT forms an arc concaved toward south and coincides well with the intermediate-depth earthquakes around the Pamir region in both polarity and location. More importantly, Figure 2 shows a distinct feature that has never been revealed before: Some intermediate-depth earthquakes with $m_{\mathrm{b}}$ magnitude around 4.0 and depth greater than $150 \mathrm{~km}$ appear to the south of $36^{\circ} \mathrm{N}$. Because the magnitudes of this group of earthquakes are small, their initial locations are poor in precision. So they might be discarded before relocation in previous research (e.g., Engdahl et al, 1998; Pegler and Das, 1998; Pavlis and Das, 2000). Here we do not discard any event beforehand. We reserve this group of events because they indeed satisfy the precision requirement finally.

Like Lou et al (2007), we used 3-D animation and a series of cross sections to study the detailed spatial distribution of the earthquakes in the Pamir and Hindu Kush region. Figure 3 shows the 15 vertical cross -sections on which hypocenters are projected. The horizontal locations of the profiles (generally perpendicular to the strike of the intermediate seismic zone) are shown by the red lines in Figure 2. Profiles $A A^{\prime}-G G^{\prime}$ are $20 \mathrm{~km}$ wide, profiles $H H^{\prime}-L L^{\prime}$ are $40 \mathrm{~km}$ wide, and profiles $M M^{\prime}-O O^{\prime}$ are $60 \mathrm{~km}$ wide. 


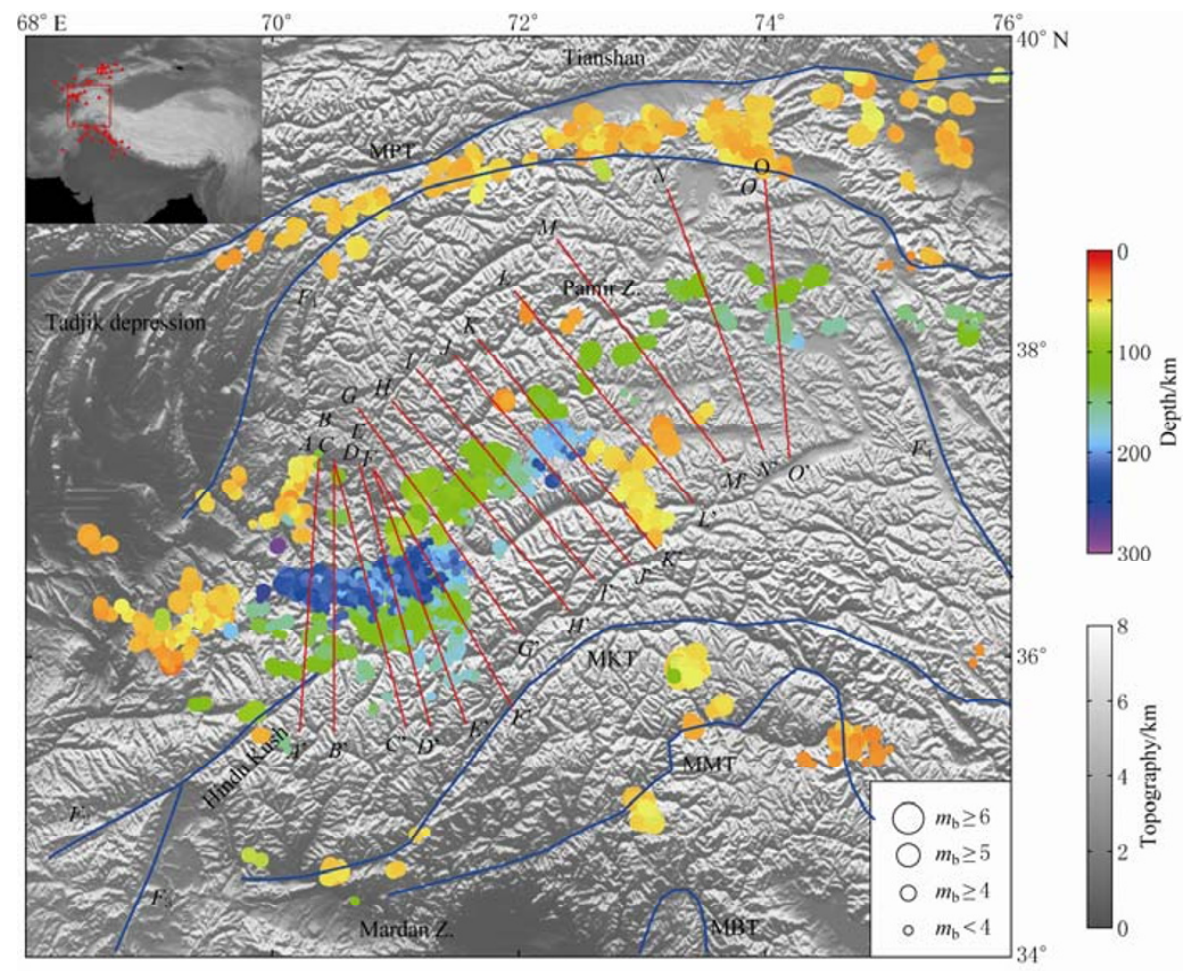

Figure 2 Epicentral distribution of the relocated earthquakes in the Pamir-Hindu Kush region. Upper left inset shows the geographic location of the research area and the distribution of the WWSSN (red triangles), of which the data are used in the earthquake relocation of this paper. Earthquakes of different magnitudes are represented by circles with different size, which are filled with colors according to the depths of the hypocenters. Solid red lines marked by AA' OO' represent the locations of the 15 vertical profiles. GMT (Wessel and Smith, 1998) is used in the visualization and the topography data is from GTOPO30 (http://edc.usgs.gov/products/elevation/gtopo30/gtopo30.html).

The western Hindu Kush segment of the W-B zone (around profiles $A A^{\prime}$ and $B B^{\prime}$ ) strikes WNW-ESE and dips NNE as mentioned by Lou et al (2007). It may be divided into the upper part and the lower part, between which there is an obvious seismic gap mentioned by Roecker et al (1980) and Lou et al (2007). The upper part has smaller dip angle and the seismicity is less active. The lower part dips nearly vertically and seems to overturn a little in profile $A A^{\prime}$ ' to $C C^{\prime}$.

The eastern Hindu Kush segment (around profiles $D D^{\prime}, E E^{\prime}$ and $F F^{\prime}$ ) strikes nearly WSW-ENE and dips NNW. In this segment, the intermediate-depth earthquakes also consist of the upper and the lower parts. But the upper part in the eastern Hindu Kush segment has greater dip angle than that in the western Hindu Kush segment. From Figures 3a-3e we may see that the dip angle of the upper part of the Hindu Kush W-B zone increases gradually from west to east. However, as our profiles are not exactly along the dip direction of the W-B zone, this variation is magnified by the misdirected projection. The inconformity in the western part of
Hindu Kush is relatively greater.

The abrupt change of the dip angle and the obvious gap in the W-B zone, which are shown in the profiles $A A^{\prime}$ to $E E^{\prime}$ ' in Figures $3 \mathrm{a}-3 \mathrm{e}$, further substantiate the decoupling between the continental plate in shallower depth and the oceanic plate in larger depth. A more interesting feature is the double-layered W-B zones in Figures $3 \mathrm{~d}-3 \mathrm{e}$, of which the lower layer corresponds to the blue dots to the south of $36^{\circ} \mathrm{N}$ in Figure 2. Both layers are composed of two parts: the upper part and the lower part. This is similar to Figures $3 a-3 c$ and the upper layers of the double-layered W-B zones in Figures $3 d-3 e$ have better continuity. Figures $3 \mathrm{c}$ and $3 \mathrm{f}$ also have double-layered W-B zones although their interlayer gaps are smaller. The overturning in Figure $3 \mathrm{~b}$ might be the expression of double-layered W-B zone too. Considering the consistency of this feature as well as our tests mentioned above, we think that the double-layered W-B zone in the Hindu Kush region is not an artifact. Ning and Zang (1990) displayed part of this feature and reported it as a fork-shaped structure. Pegler and Das 

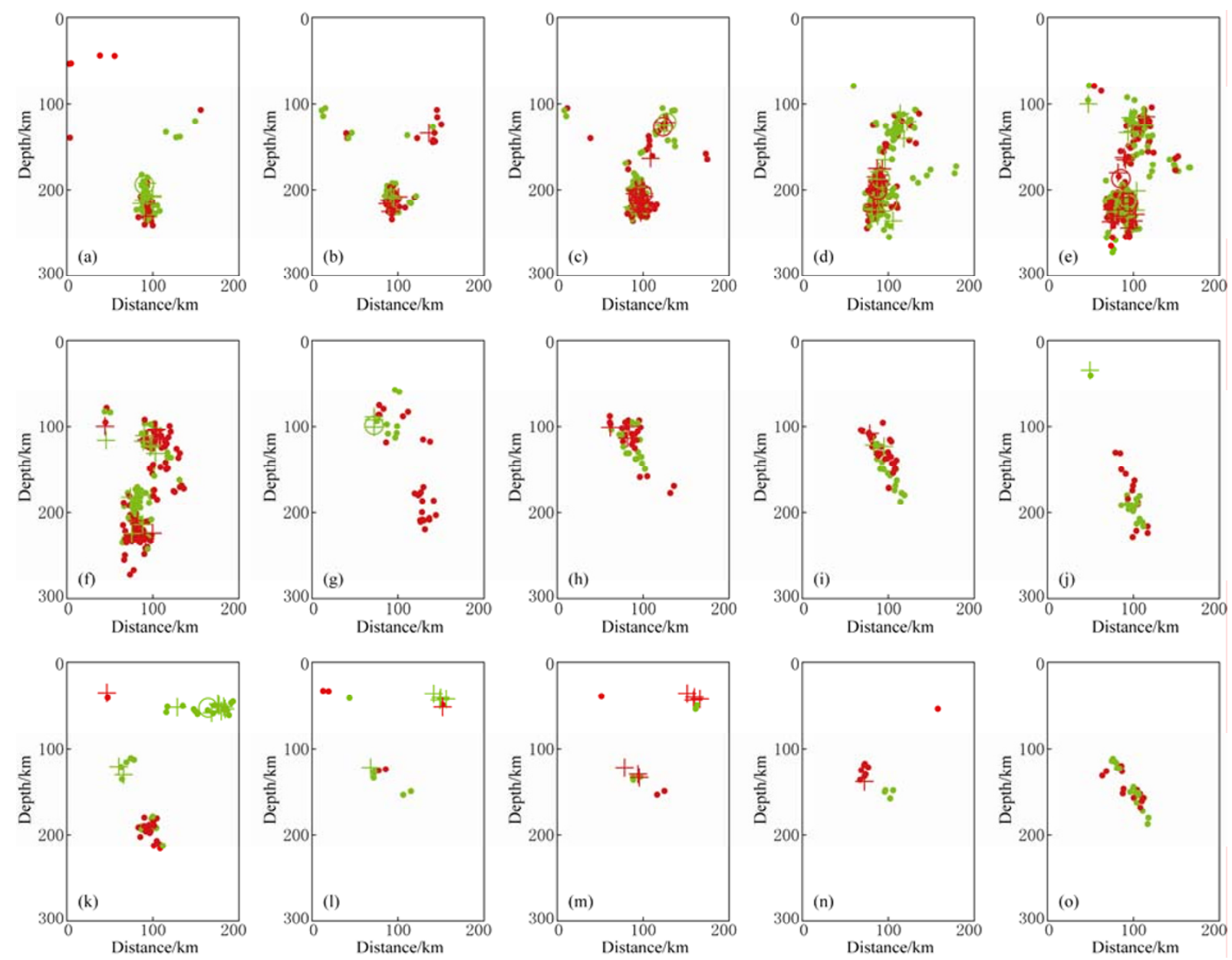

Figure 3 Vertical cross sections $A A^{\prime}-O O^{\prime}$ of earthquakes in the Pamir-Hindu Kush region. The locations of these cross sections are shown in Figure 2. Red and green symbols represent earthquakes at the left and right sides of the profiles, respectively (taking $A A$ ' as an example, left or right is assigned when one stands at $A^{\prime}$ and looks at $A$ ). Circles are the events with body wave magnitude greater than 6.0, crosses are those with body wave magnitude greater than 5.0, dots are those with body wave magnitude smaller than 5.0.

(1998) also clearly showed part of this feature although they did not offer any explanation. Lou et al (2007) clearly showed that there are double seismic layers in the eastern Hindu-Kush segment although they did not reveal the upward extension of the lower layer because low magnitude earthquakes were not used. Our image of the double-layered W-B zone in the Hindu Kush region is different from previous studies. The earthquake hypocenters clearly delineate two subducting slabs instead of one. The two slabs are currently near each other but they might be distant originally.

Seismicity in the Pamir region is not as active as in the Hindu Kush region. Although there are less earthquakes than Lou et al (2007) displayed, Figures 3g-3o still clearly show declined earthquake belts below $100 \mathrm{~km}$ depth. The dip direction changes gradually from southeast at its western end to south at its eastern end. Unlike Hindu Kush, the W-B zone in the Pamir region does not have double-layered structure. The alignment of the Pamir and the Hindu Kush seismic zones around the boundary region is the main argument for the one-slab tear model (Billington et al, 1977; Pavlis and Das, 2000). However, the geometric structure differences in the two regions make the one-slab tear model unreasonable.

Figures $3 \mathrm{f}-3 \mathrm{~g}$ also show a contact relation between the W-B zones in Hindu Kush and in Pamir. The two W-B zones are obviously different in geometry and are not tightly-fitted with each other. However, they contact at a depth of about $130 \mathrm{~km}$. At the boundary region they form back-to-back bow shapes as shown in Figure 3f. This clearly expressed feature gainsays the expression 
that a gap exists between the W-B zones in Hindu Kush and Pamir, so the possibility that the earthquakes occur on two independently subducted slabs should be excluded too. On the contrary, the contact relation between these two back-to-back arcs strongly implies that the earthquakes occurred on two different plates colliding with each other. The Harvard CMT solutions further substantiate that the deeper parts of the W-B zones in Hindu Kush represent detached parts of formerly subducted slabs because the Harvard CMT solutions exhibit less regular patterns both at the bottom of the upper W-B zone and at the bottom of the lower W-B zone. As mentioned above as well as in Lou et al (2007), earthquake distributions in Figure 3 clearly show that there is seismic gap in the W-B zone in the Hindu Kush region at about 170-200 km depth, which divides the W-B zone into upper and lower parts of earthquake concentration. The relative irregularity of focal mechanism solutions at the bottom of the two parts might be caused by slab bending and breaking off. The transition area from continental to oceanic crust is easy to be bent and yielded. As a result, there are few earthquakes taking place there and the gap is generated. The loose connection between the upper and lower parts reduces the drag force from below due to gravity and results in irregular focal mechanisms at the bottom of the upper part of the W-B zone. The stronger and thinner oceanic crust results in denser and thinner W-B zone below $200 \mathrm{~km}$ in the east end of the Hindu Kush zone. High velocity at depth greater than $200 \mathrm{~km}$ and low velocity above $200 \mathrm{~km}$ revealed by some tomographic images (Vinnik et al, 1977; Roecker, 1982; Hamburger, et al, 1992; Mellors et al, 1995) are consistent with the idea of transition from a continental slab to an oceanic slab. However, tomographic features showed by different authors are different and need further confirmation (Koulakov and Sobolev, 2006; Huang and Zhao, 2006)

Secondly, the Harvard CMT solutions in the double-layered W-B zone in Hindu Kush does not exhibit systematic differences between the two layers (Lou et al, 2007), which further validates that the earthquake hypocenters of the double-layered W-B zone in Hindu Kush region delineate two subducting slabs. The two ophiolite belts facing north around the Gardez-Mardan zone (Verma and Sekhar, 1985) are most probably the geochemical signatures of those subducted slabs at the Earth's surface.

Most importantly, the Harvard CMT solutions of the intermediate-depth earthquakes in the Pamir-Hindu
Kush region provide strong evidences for the colliding relationship between the opposite subducted slabs. The $P$ axes of the intermediate-depth earthquakes at both sides of the Pamir-Hindu Kush boundary region are sub-horizontal and are roughly north-south (Lou et al, 2007), which reflects a strong compression as a result of collision and definitely contradicts the tear model. From southwest to northeast, horizontal along strike axis of the focal mechanism solutions in the Pamir region changes from $P$ to $B$ and then $T$; and the $P$ axes gradually change to being perpendicular to the strike of the W-B zone, which reflect attenuation of compression exerted by the deep subducted Hindu Kush slab at about $130 \mathrm{~km}$ depth.

\section{Conclusions}

We have relocated the earthquakes in the $\mathrm{Pa}$ mir-Hindu Kush region in 1964-2003 using the catalog $\mathrm{P}$ and $\mathrm{S}$ arrival times from the ISC and the double-difference method (Waldhauser and Ellsworth, 2000; Waldhauser, 2001). The spatial distribution of the hypocenters of the relocated intermediate-depth earthquakes gave an improved and more comprehensive image of the double-layered W-B zone beneath Hindu Kush than previous studies. Both layers are composed of two parts: the upper part and the lower part. This feature has never been revealed before. The W-B zone beneath Pamir is totally different: it does not have a double-layered structure. The W-B zone in Hindu Kush and the one in Pamir meet with each other at the depth of about $130 \mathrm{~km}$ and form back-to-back bow shapes in the boundary region. And the Harvard CMT solutions of this boundary region show near horizontal along strike compression. Combining the above results with tomographic and geochemical evidences, we propose that there are opposing subductions in the Pamir-Hindu Kush region. The two subducted slabs are colliding with each other at about $130 \mathrm{~km}$ depth.

This new model is different from the previous opposing subduction model (Roecker et al, 1980; Chatelain et al, 1980; Ning and Zang, 1990; Fan et al, 1994; Lou et al, 2007) in terms of the collision between the Pamir subduction zone and the Hindu Kush subduction zone. Our conclusions are not based on the possibly inexistent seismic gap between the two W-B zones, but based on the unambiguous contact of the two W-B zones and the regular pattern of the stress state in this region. Geometrical consistency between the two seismic zones 
is the natural result of the collision. Our model also naturally relates the intermediate-depth earthquakes under the Pamir and the intense shallow earthquakes along the northern boundary of the Pamir in Tadjikistan. Ophiolite belt facing south in northern Pamir zone (Verma and Sekhar, 1985) forms its geochemical evidence. Moreover, we find a way out of the difficulty that Punjab Wedge could not supply enough material diversely subducting into deep Earth in the Pamir region although it can exert strong extrusion to Pamir zone. The south-concaved northern Pamir arc, instead of the plate coming from south, can be the source for enough subducting materials beneath Pamir.

Acknowledgements This work was partly supported by the National Fundamental Science Program of China under (No. 2004cb418406), the National Natural Science Foundation of China (No.90814002) and Key Projects in the National Science \& Technology Pillar Program during the Eleventh Five-year Plan Period (No. 2008BAC38B02-4). We thank two anonymous reviewers for their helpful comments and suggestions on the manuscript.

\section{References}

Billington S, Isacks B L and Barazangi M (1977). Spatial distribution and focal mechanisms of mantle earthquakes in the Hindu Kush-Pamir region: A contorted Benioff zone. Geology 5: 699-704.

Chatelain J L, Roecker S W, Hatzfeld D and Molnar P (1980). Microearthquake seismicity and fault plane solutions in the Hindu Kush region and their tectonic implications. J Geophys Res 85: 1 365-1 387.

Efron B (1982). The jacknife, the bootstrap, and other resampling plans. SIAM, Philadelphia, 92.

Engdahl E R, van der Hilst R and Buland R (1998). Global teleseismic earthquake relocation with improved travel times and procedures for depth determination. Bull Seism Soc Amer 88: 722-743.

Fan G W, Ni J F and Wallace T C (1994). Active tectonics of the Pamirs and Karakorum. J Geophys Res 99: 7 131-7 160.

Gutenberg B and Richter C F (1954). Seismicity of the Earth and Associated Phenomena. Princeton University Press, Princeton, NJ, 310.

Hamburger M W, Sarewitz D R, Palvis T L and Popandopulo G A (1992). Structural and seismic evidence for intracontinental subduction in the Peter the First Range, central Asia. Geol Soc Amer Bull 104: 397-408.

Huang J and Zhao D (2006). High-resolution mantle tomography of China and surrounding regions. J Geophys Res 111: B09305, doi:10.1029/2005JB004066.

Koulakov I and Sobolev S V (2006). A tomographic image of Indian lithosphere break-off beneath the Pamir-Hindukush region. Geophys J Int 164: $425-440$.
Lei J S, Zhou H L and Zhao D P (2002). 3-D velocity structure of P-wave in the crust and upper-mantle beneath Pamir and adjacent region. Chinese $J$ Geophys 45: 802-812 (in Chinese with English abstract).

Liu Q H (1999). Research on the Hindu Kush-Pamir intermediate-depth seismic zone. Acta Seismologica Sinica 21: 233-240 (in Chinese with English abstract).

Lou X T, Diao G L, Ye G Y and Ning J Y (2007). Spatial distribution of intermediate earthquakes and focal mechanism solutions in the Pamir-Hindu Kush region. Chinese J Geophy 50: 1448-1 455.

Mellors R J, Pavlis G L, Hamburger M W, Al-shukri H J and Lukk A A (1995). Evidence for a high-velocity slab associated with the Hindu Kush seismic zone. J Geophys Res 100: 4 067-4 078.

Negredo A M, Replumaz A, Villasenor A and Guillot S (2007). Modeling the evolution of continental subduction processes in the Pamir-Hindu Kush region. Earth Planet Sci Lett 259: 212-225.

Ning J Y and Zang S X (1990). The distribution of earthquakes and stress state in Pamir-Hindu Kush regions. Acta Geophysica Sinica 33: 657-669 (in Chinese with English abstract).

Nowroozi A A (1971). Seismo-tectonics of the Persian plateau, eastern Turkey, Caucasus, and Hindu-Kush regions. Bull Seism Soc Amer 61: 317-341.

Pavlis G L and Das S (2000). The Pamir-Hindu Kush Seismic zone as a strain marker for flow in the upper mantle. Tectonics 19: 103-115.

Pegler G and Das S (1998). An enhanced image of the Pamir-Hindu Kush seismic zone from relocated earthquake hypocenters. Geophys $J$ Int $\mathbf{1 3 4}$ : $573-595$.

Richter C F (1958). Elementary Seismology. W H Freeman \& Co., San Francisco, CA, 768 pp.

Roecker S W, Soboleva O V, Nersesov I L, Lukk A A, Hatzfeld D, Chatelain J L and Molnar P (1980). Seismicity and fault plane solutions of intermediate depth earthquakes in the Pamir-Hindu Kush region. $J$ Geophys Res 85: 1358-1 364.

Roecker S W (1982). Velocity structure of the Pamir Hindu Kush region: Possible evidence of subducted crust. J Geophys Res 87: 945-959.

Tian Y and Chen X F (2005). A rapid and accurate two-point ray tracing method in horizontally layered velocity model. Acta Seismologica Sinica 27: 147-154 (in Chinese).

Van der Voo R, Spakman W and Bijwaard H (1999). Tethyan subducted slabs under India. Earth Planet Sci Lett 171: 7-20.

Verma R K and Sekhar C C (1985). Seismotectonics and focal mechanisms of earthquakes from Pamir- Hindu Kush regions. Tetonophysics 112: 297-324.

Vinnik L P, Lukk A A and Nersesov I L (1977). Nature of the intermediate seismic zone in the mantle of the Pamir-Hindu Kush. Tectonophysics 28: T9-T14.

Waldhauser F and Ellsworth W L (2000). A double-difference earthquake location algorithm: Method and application to the northern Hayward fault. California. Bull Seism Soc Amer 90: 1353-1 368.

Waldhauser F (2001). HypoDD: A program to compute double-difference hypocenter locations. U.S. Geological Survey Open-File Report, 01-113.

Wessel P and Smith W H F (1998). New, improved version of the Generic Mapping Tools released. EOS Trans. AGU 79: 579.

Zhu L P, Helmberger D V, Saikia C K and Woods B B (1997). Regional waveform calibration in the Pamir-Hindu Kush region. $J$ Geophys Res 102: $22799-22813$. 